\title{
A escola na perspectiva de adolescentes da Geração Z
}

\author{
Ana Flávia Campeiz ${ }^{1}$, Wanderlei Abadio de Oliveira ${ }^{2}$, Luciana Mara Monti Fonseca ${ }^{3}$, \\ Luciane Sá de Andrade ${ }^{4}$, Marta Angélica lossi Silva ${ }^{5}$
}

\footnotetext{
${ }^{1}$ Psicóloga, Discente do Programa de PósGraduação em Enfermagem em Saúde da Escola de Enfermagem de Ribeirão Preto da Universidade de São Paulo. Ribeirão Preto, SP, Brasil. E-mail: fafacampeiz@hotmail.com.

${ }^{2}$ Psicólogo, Doutor em Enfermagem em Saúde Pública. Professor Contratado III da Escola de Enfermagem de Ribeirão Preto da Universidade de São Paulo. Ribeirão Preto, SP, Brasil. E-mail: wanderleio@usp.br.

${ }^{3}$ Enfermeira, Doutora em Enfermagem em Saúde Pública. Professora Associada da Escola de Enfermagem de Ribeirão Preto da Universidade de São Paulo. Ribeirão Preto, SP, Brasil. E-mail: lumonti@eerp.usp.br.

${ }^{4}$ Psicóloga, Doutora em Educação. Professora Doutora da Escola de Enfermagem de Ribeirão Preto da Universidade de São Paulo. Ribeirão Preto, SP, Brasil. E-mail:

lucianeandrade@eerp.usp.br.

${ }^{5}$ Enfermeira, Doutora em Enfermagem em Saúde Pública. Professora Associada da Escola de Enfermagem de Ribeirão Preto da Universidade de São Paulo. Ribeirão Preto, SP, Brasil. E-mail: maiossi@eerp.usp.br.
}

Recebido: 01/03/2017.

Aceito: 23/10/2017.

Publicado: 31/12/2017.

Como citar esse artigo:

Campeiz AF, Oliveira WA, Fonseca LMM, Andrade LS, Silva MAI. A escola na perspectiva de adolescentes da Geração Z. Rev. Eletr. Enf. [Internet]. 2017 [acesso em: ____;19:a58. Disponível em: http://doi.org/10.5216/ree.v19.45666.

\section{RESUMO}

Objetivou-se analisar o sentido da escola para estudantes da Geração Z de uma escola de Ensino Médio de uma capital do norte brasileiro. Estudo qualitativo do qual participaram 57 adolescentes. A coleta de dados ocorreu por meio de grupos focais e analisados por meio da análise de conteúdo, modalidade temática. Os resultados evidenciaram dois núcleos temáticos: Escola, espaço para aprender e preparar para o futuro e, Impasses e em passos, construindo novas perspectivas sobre a escola. Os adolescentes compreendem a escola como espaço de construção da aprendizagem, porém consideram o ambiente virtual também como espaço de construir conhecimento. Esse estudo oferece contribuições para repensar a educação direcionada à geração digital, no sentido de incorporar ao ensino novas linguagens e inovações, além de orientar a definição de planos e linhas de cuidado e atenção à saúde que considerem as novas relações entre os adolescentes e a tecnologia.

Descritores: Educação; Tecnologia de Informação; Adolescentes; Enfermagem Pediátrica.

\section{INTRODUÇÃO}

A adolescência é um momento do desenvolvimento humano marcado por processos de transformação. Os adolescentes são sujeitos ativos, capazes de ter e incorporar valores à sociedade contemporânea $^{(1)}$. Essas características dificultam, muitas vezes, a construção de modelos de atenção capazes de favorecer nesse momento peculiar da vida o protagonismo, a autonomia e o cuidado

consigo e com o outro. Assim sendo, esse estudo oferece de forma original subsídios para compreender as percepções e os sentidos sobre escola e o processo ensino-aprendizagem de adolescentes da era digital e 
que poderá auxiliar profissionais da atenção primária na construção de estratégias de educação em saúde para esse público.

A era digital é um fenômeno que influi diretamente o espaço escolar, principalmente quando os estudantes estão em constante interação com as Tecnologias de Informação e Comunicação (TICs). Dessa era surgiram os nativos digitais, como são conhecidas as crianças nascidas depois de 1980 e os adolescentes que fazem uso constante de dispositivos tecnológicos de comunicação e entretenimento ${ }^{(2)}$, permanecendo conectados e integrando as tecnologias em suas vidas ${ }^{(2-3)}$. Esse grupo é classificado em duas gerações: geração "Y" - nascidos entre 1980 e 1990; e geração "Z" - nascidos a partir de 1990 ${ }^{(4)}$.

As TICs devem ser compreendidas enquanto ferramentas que potencializam a aprendizagem, na medida em que são incluídos games, portfólios online, programas virtuais e aplicativos de dispositivos móveis, por conseguirem atrair a atenção e assim alcançar os estudantes nativos digitais ${ }^{(5)}$. Pesquisas recentes ${ }^{(4,6)}$, também enfatizam demandas por inovação e uso das tecnologias para as quais a escola precisa estar atenta para atender as necessidades de formação e desenvolvimento dos estudantes. Essas ideias e demandas podem ser ampliadas para outras áreas, como a saúde.

Nesse sentido, percebe-se que enfermeiros e outros profissionais da saúde na atenção primária encontram dificuldades em oferecer ações de educação e promoção de saúde junto aos adolescentes. Para a área, esse momento de desenvolvimento possui modos diferentes de lidar com a saúde e seus processos, o que resulta na interpretação de que sempre será um trabalho árduo e com obstáculos ${ }^{(7)}$. Para minimizar essa dificuldade é necessário compreender como esse público se expressa na contemporaneidade e como é o seu modo de aprender e se envolver no processo-aprendizagem. Dessa forma, objetivou-se conhecer o sentido construído pelos estudantes Geração Z em relação a escola.

\section{MÉTODO}

Estudo descritivo, de abordagem qualitativa, realizado em uma escola pública de Palmas/TO, Brasil com 57 estudantes adolescentes do EM (56\% meninas) que aceitaram espontaneamente participar do estudo, sendo $38,60 \%$ do primeiro ano, $31,57 \%$ do segundo ano e $29,83 \%$ do terceiro ano. Como critério de inclusão participaram adolescentes regularmente matriculados e frequentes no ensino médio no momento da pesquisa, nascidos a partir de 1990, ou seja, pertencentes a Geração Z, de acordo com referencial adotado para esta investigação ${ }^{(4)}$. Como critério de exclusão, não se considerou adolescentes nascidos antes de 1990.

Os dados foram coletados no período de novembro a março de 2017 , por meio de um questionário fechado, para conhecer o perfil dos participantes, que contemplou dados relacionados ao perfil sociodemográfico e condições de acesso à internet, e realização de grupos focais (GF).

Realizou-se seis sessões de GF. Essa técnica permitiu construir espaços que propiciaram a fala e escuta qualificada, além da problematização sobre os temas abordados, a partir de discussões planejadas e reflexivas acerca do fenômeno estudado ${ }^{(8-9)}$. As sessões foram realizadas na escola, no horário de aula dos estudantes, com anuência dos gestores escolares, professores e alunos. Foram realizados dois grupos focais 
com cada ano escolar. As sessões foram gravadas e posteriormente transcritas. Com o objetivo de garantir o anonimato dos grupos e sujeitos da pesquisa, utilizou-se a identificação dos grupos focais somente como GF I, GF II, e assim suscessivamente.

Os grupos focais foram orientados por um roteiro pré-estabelecido que continha a pergunta disparadora: "Qual a função da escola para você?". Na sequência, perguntas que permeiam o tema em foco, tais como, a importância da escola, como descrevem e vivenciam suas experiências escolares, como as TICs se apresentam no âmbito escolar e no processo ensino-aprendizagem, qual a visão sobre a escola, como os adolescentes percebem a escola e sua interface com os meios digitais, a relação dos dispositivos disponíveis e sua utilização, entre outras. O segundo encontro aprofundou questões e reflexão sobre o assunto em pauta.

A análise dos dados ocorreu por meio da análise de conteúdo, modalidade temática, proposta por $\operatorname{Bardin}^{(10)}$, que prima pela identificação das unidades de sentido/expressões chaves, a partir da interpretação dos conteúdos dos dados, que se constituem em núcleos temáticos de análise. A trajetória analíticointerpretativa percorreu as seguintes etapas: contato exaustivo com o material; apreensão das particularidades do material; organização do material; codificação; exploração do material e elaboração da síntese interpretativa ${ }^{(9-10)}$. Foram identificados dois núcleos temáticos: Escola, espaço para aprender e preparar para o futuro; e Impasses e em passos, a escola que precisa se redescobrir. O referencial vigotskiano $^{(11)}$ foi utilizado na análise dos dados.

O projeto de pesquisa foi avaliado e aprovado pelo Comitê de Ética em Pesquisa (CEP) da Escola de Enfermagem de Ribeirão Preto da Universidade de São Paulo (Parecer no 1401216). Seguindo todas as orientações da regulamentação brasileira para pesquisas com seres humanos os adolescentes somente participaram após seu assentimento e o consentimento livre esclarecido de seus responsáveis.

\section{RESULTADOS}

As idades dos adolescentes variaram entre 14 e 19 anos. No que tange ao acesso à mídia, evidenciouse que os participantes obtêm informações sobre os mais diferentes assuntos prioritariamente por meio da internet (96,49\%). Quanto ao acesso ao computador e internet, 92,98\% disseram ter acesso ao computador e 96,50\% tem acesso à internet. 0 tempo despendido no uso da internet, 40,35\% permanecem online de três a cinco horas por dia e $35,08 \%$ permanecem online mais que oito horas diárias.

\section{Escola, espaço para aprender e preparar para o futuro}

Identificou-se o sentido da prática educacional escolar a partir da construção do conhecimento e a expectativa que se forma a partir desta relação. As falas dos participantes apontam, num primeiro momento, a escola, como local de ensino e a formação regular, e consequentemente, com a finalidade de preparar para o mundo do trabalho. Acresce-se a isso a percepção dos estudantes de que a escola deve instruí-los e orientálos: 
Tem coisas que a gente faz no dia-a-dia que fui entender seu funcionamento aqui na escola. Então acho que a escola tem essa função de explicar, mostrar, ensinar. (GFI)

[...] acho que na vida de qualquer um tem a função de formar e me preparar para o trabalho. (GF II)

Os discursos enfatizam a função da escola de alfabetizar e, de explicar e ensinar e para que os estudantes aprendam "tudo". Entretanto a percepção dos estudantes sobre a escola não se reduz à ideia passiva de receber informações sem o processo de elaboração, mas é destinada à organização das informações, o que propicia a construção do conhecimento, como citado:

... a escola me ajuda a organizar o que aprendo. (GF II)

Além disso, o aprendizado pelos nativos digitais é motivado ao colocar em prática o que é estudado e vão em busca de meios que lhes possam proporcionar isso, visando sair do "plano das ideias" e assim colocar "as coisas em prática":

Eu gosto de fazer as coisas, não sou bom de ficar no plano das ideias, gosto de colocar as coisas em prática. Exemplo em geografia, vemos as guerras, mas não tem nada além da escrita do livro e a fala do professor, então acho que poderia colocar música, mais fotos. Então eu já procuro como são feito as bombas, porque eu curto química, vou estudando isso por fora. (GF II)

Os discursos demonstram uma representação tradicional dos adolescentes sobre a escola, considerada como focada no "teórico" e no "plano das ideias" o que não é visto com entusiasmo pelos estudantes, enquanto sentem a vontade de querer perceber o fenômeno na "prática". Nota-se aqui também, a ausência de estratégias pedagógicas que envolvam os estudantes e estimule maior engajamento deles.

Há uma percepção de que os sentidos da escola são relacionados com o mundo do trabalho. Ela ajuda na possibilidade de um futuro emprego, por meio das aprendizagens e conhecimentos proporcionados, assim como possui outros sentidos para aqueles que querem ingressar na universidade (melhorar de vida).

[...] a função [da escola] é me alfabetizar, formar e me preparar para a faculdade e mercado de trabalho... dar o mínimo de condição para que eu seja capaz de ter uma profissão. (GF III)

Eu pesquiso muito sobre agronomia, veterinária, a economia na internet. Quero fazer faculdade de engenheiro agrônomo ou veterinária. (GF III)

Impasses e em passos, a escola que precisa se redescobrir

Os adolescentes da Geração Z apresentaram dificuldades de adaptação ao espaço escolar e descontentamentos às metodologias tradicionais de ensino-aprendizagem ainda vigentes e que não correspondem mais às suas necessidades. As demandas dos estudantes da nova geração reforçam a necessidade de atualização das metodologias para melhor compreensão do conteúdo ministrado, como se observa nos trechos a seguir:

Não tem instrumentos a não ser o quadro, se utilizassem, a aula seria mais legal, passaria mais rápido e também 
poderíamos ver os exemplos, não só ficar imaginando. (GFI)

Acho que a tecnologia só vem para ajudar. Quando tem filme, alguém falta? Não. Quando tem qualquer evento de feira de profissão e ciência, alguém falta? Não. Quando tem que trazer música, fazer teatro, alguém falta? Não. (GF II)

Noutra direção, a propagação de mídias e TICs e seu avanço constante, implica mudança de papéis nos professores que passam a ser mediadores de informações:

Ficamos muito tempo mexendo no celular no horário de aula, mas às vezes é porque a aula está muito chata, com sono, tirando as vezes que você percebe nitidamente que a professora não domina o assunto, aí na aula mesmo vou procurando vídeos no Youtube sobre o assunto, [...] a í fico assistindo na sala mesmo com o fone de ouvido ou em casa, para entender melhor a matéria. (GFI)

A falta de instrumentos digitais também foi pontuada por estudantes que já tiveram experiência em escolas privadas. A comparação entre escola pública e privada narrada pelos estudantes sintetiza o desejo por uma escola pública com qualidade:

Os aparelhos de som, DVD, slides, não atrapalham de jeito nenhum. Só ajudariam a aula não ficar cansativa e, às vezes, chata. Minha opinião é que a escola tem que investir nisso. (GFI)

Mesmo que tenha sala de vídeos, Datashow, laboratório de informática, os professores não usam, a maioria dos professores só passam toda a matéria em torno dos livros e com isso toda aula fica sempre a mesma coisa. Acho que os professores podiam pensar nisso, mas aqui também está uma contenção de custo que a energia seria gasta, então eles utilizam isso para não usar. (GF II)

\section{DISCUSSÃO}

Para os participantes a escola ainda é percebida como local privilegiado de formação, mas que concorre, atualmente, com os dispositivos móveis e o acesso à internet que, em alguma medida, socializou o conhecimento. Pelos discursos dos adolescentes se pode inferir que a construção do conhecimento por meio da experiência com o outro e o mundo assim, o contexto histórico e cultural dos adolescentes, nativos digitais, dão sentido e embasamento da sua aprendizagem, que se dá em contato com o outro em diversos espaços cotidianos, inclusive o virtual ${ }^{(11)}$.

Outra constatação desse estudo se refere ao modo de aprender dos adolescentes. Os nativos digitais não querem aprender para depois praticar, mas utilizam para a aprendizagem o método de tentativa e erro, uma vez que não têm medo de cometer erros e assim aprendem mais fácil ${ }^{(12)}$. Portanto, o que antes tínhamos como pressupostos pedagógicos, de se aprender e depois praticar, hoje, os novos paradigmas de ensino e aprendizagem trazem a racionalidade prática e crítica como perspectiva, onde a aprendizagem deve se dar por meio de situações práticas que sejam efetivamente significativas, problematizadoras e reflexivas. Nesse sentido, a ênfase em um modelo de educação em saúde crítico, com expressão promocional da saúde e a atuação de equipes de saúde nas escolas é consistente com a perspectiva de se combinar níveis de intervenções capazes de empoderar os sujeitos para o processo de transformação de fatores vulnerabilizantes que incidem sobre a sua saúde, valendo-se de estratégias de educação em saúde ativas e participativas $^{(13-14)}$. 
Desse modo, o uso da tecnologia para complementar a aprendizagem em sala de aula, considerando esses os meios familiarizados pelos estudantes, possibilita desenvolver novas formas interativas e colaborativas de aprendizagem ${ }^{(12)}$ tornando-se uma alternativa aos paradigmas tradicionais do processo de ensino-aprendizagem. Não obstante, as TICs enquanto recursos tecnológicos educacionais apresentam benefícios que ultrapassam as competências acadêmicas ligadas à cognição, mas permitem o desenvolvimento da autonomia nas esferas intelectual e comportamental, haja vista que os próprios estudantes partem para a busca da solução dos desafios encontrados em seu cotidiano ${ }^{(15)}$. Há aqui um indicador importante para a tomada de decisão sobre a necessidade de se repensar e reformar os planos e linhas de cuidado em saúde para os adolescentes em idade escolar ${ }^{(13)}$ da Geração Z.

Nesta perspectiva, corroboram estudos recentes ${ }^{(16-19)}$ sobre jogos eletrônicos no qual a educação torna-se o objetivo principal ${ }^{(18)}$. Esse recurso didático tecnológico é capaz de motivar o processo de aprendizado da criança e estimular mudanças de comportamento ao integrar características lúdicas a conteúdos específicos $^{(16,18)}$, desse modo conseguem atingir o objetivo de educação em saúde, apresentando êxito na terapêutica de doenças crônicas e tratamento psicológicos ${ }^{(17)}$, abordagem da sexualidade na adolescência, bem como no auxílio ao enfrentamento da obesidade infantil ${ }^{(18)}$. Assim, é considerado como estratégia potente para a promoção de saúde ${ }^{(18,20)}$.

Para tanto, há que se considerar também que, a escola tem como desafio o acompanhamento do conhecimento que os estudantes constroem fora dela. Uma das formas de motivar e atrair novos estudantes é se aproximar de suas vivências e experiências cotidianas. Por vezes, o conhecimento veiculado e construído na escola não faz sentido para os estudantes, entretanto, o contato com mídias, celular, internet, rede social, passam a ser mais interessantes configurando uma maior identificação ${ }^{(15)}$. Esses desafios não se colocam apenas para a área da educação, mas também para profissionais de outras áreas, como a saúde, que lidam e se relacionam com os alunos, devendo assim, se prepararem para usar a seu favor as mídias e os recursos digitais.

Por outro lado, a escola também é associada à preparação para o futuro profissional e a melhores condições de inserção no mundo do trabalho ${ }^{(20-21)}$. Dessa forma, os estudantes valorizam a escola que thes oferecem apoio e suporte para o exercício do trabalho, sendo possível compreender o conhecimento como algo que deve ser útil para o exercício de uma profissão específica ou possibilitar a inserção direta no mundo do trabalho, constituindo então a escolarização como pressuposto de empregabilidade.

Nesse sentido, a abordagem vygotskiana pode trazer implicações significativas para a compreensão desse processo de aproximação dos estudantes com os espaços educacionais e seus instrumentos. Essa aproximação exige a interação entre as pessoas e, nos tempos atuais, reflexões sobre quais os elementos são utilizados como mediadores no processo de ensino-aprendizagem ${ }^{(11)}$. No cenário apresentado pelos participantes a tecnologia se apresenta como um novo instrumento capaz de transformar a própria natureza humana e, por consequência, transforma a ação coletiva e os meios de comunicação que serão basilares para definir como eles aprendem. 
No conjunto, os dados também revelaram necessidades por atualização e utilização de novos recursos pedagógicos. Enfatizou-se a ausência de instrumentos, técnicas e estratégias dinâmicas capazes de atrair os estudantes nativos digitais. O distanciamento da escola em relação ao uso das TICs em sala de aula é uma observação constante dos estudantes, já que esses as consideram como ferramentas motivadoras para e por eles $^{(15)}$. Pensando em novas práticas eficientes para a aprendizagem e atraentes à esta geração evidencia-se como fatores fundamentais a possibilidade de que os estudantes possam atuar de forma ativa, participativa e autônoma no controle da sua aprendizagem, proporcionado pelas situações em que têm a oportunidade de experimentar ou testar suas ideias ${ }^{(22)}$.

Diante desse cenário, a necessidade de reformulação do papel dos professores que são chamados a se posicionar como facilitadores de descobertas, para que desenvolvam um trabalho de mediação entre os adolescentes e as novas tecnologias educacionais. É exigido dos professores uma readaptação e modelação das estratégias pedagógicas, das práticas motivadoras e o domínio tanto do conhecimento específico quanto de instrumentos tecnológicos. Além disso, a incorporação das TICs nos processos de ensino e aprendizagem permanece como um desafio a ser enfrentado pelas políticas públicas, sobretudo no que diz respeito à capacitação do professor como agente mediador ${ }^{(6)}$.

Essa demanda apresentada pelos participantes por desenvolvimento e capacitação dos professores, bem como aprimoramento das escolas, permitem problematizar o conceito de zona de desenvolvimento proximal (ZDP) ${ }^{(11)}$. Essa ZDP se refere a um espaço entre conhecimentos já assimilados e aqueles que dependem para se consolidarem da intervenção de outras pessoas mais experientes ou preparadas ${ }^{(11)}$. Para a Geração Z pode haver um consenso de que os professores e as escolas não são "mais experientes ou preparados" para orientá-la para a internalização de novas aprendizagens, novos comportamentos (como a adoção de hábitos de vida saudáveis, por exemplo) e novas maneiras de interpretar e existir no mundo. Observa-se que não se trata, apenas, de reformular o papel do professor, mas outros profissionais que vão atuar junto ao público adolescente precisam ter esses aspectos em perspectiva para serem eficazes na ação.

Por fim, nossos resultados sugerem que a escola permanece associada a modelos pedagógicos que não facilitam o processo ensino-aprendizagem dos adolescentes na atualidade. Para a área da saúde do escolar, problematiza-se o impacto dessas descobertas no que se refere à proposição de ações de promoção, prevenção e educação a saúde. Nesse sentido, as TICs devem ser consideradas como instrumentos valiosos para a mudança de comportamentos e a adoção de hábitos de vida saudáveis pelos adolescentes. Como se pode operacionalizar essa questão? Os participantes do estudo já indicaram as dificuldades que não são prerrogativas da educação - recursos limitados, profissionais despreparados para a nova realidade, estruturas físicas deficientes - mas já existem experiências exitosas na área da saúde como o uso de games e aplicativos que auxiliam na formação profissional em saúde, especialmente na enfermagem ${ }^{(20)}$, o trabalho de enfermeiros e outros profissionais no cuidado das populações.

A superação dessa dificuldade para a aplicação de novas tecnologias nos processos educacionais pode ser explorada a partir das perspectivas vygotskianas que coloca o outro como corresponsável pelo seu 
próprio processo de aprendizagem, mas que também nos leva a pensar como ser, na contemporaneidade, elementos que atuam na ZDP e são capazes de fazer o outro avançar no conhecimento ${ }^{(8)}$. Para a área da saúde essa ideia é central, pois as equipes de saúde precisam se comprometer com o cuidado e a educação em saúde por meio de um plano terapêutico e educacional singular, sem negligenciar como estes produzirão efeitos significativos e duradouros na vida dos adolescentes. A ideia vale para os campos da educação e da saúde do escolar, perpassando pela atuação intersetorial das diferentes equipes nesses espaços e lidando com a Geração Z, o que requer novas abordagens e processos de ensino e aprendizagem, promover saúde e estimular a adoção de hábitos de vida saudáveis.

\section{CONSIDERAÇÕES FINAIS}

À luz da percepção dos adolescentes a escola está aquém das expectativas desejadas por seus estudantes já que apresenta os impasses tanto da falta de investimento público quanto da ausência de capacitação dos atores escolares em aceitar e manejar os equipamentos e estratégias de ensino e aprendizagem que fazem sentido no seu tempo, de Geração Z. Os participantes sugerem à instituição escolar novas perspectivas para construção do conhecimento, com metodologias que expressem maior dinamicidade e aprendizagens que façam sentido, que sejam eficazes e possibilitem seu desenvolvimento e posicionamento crítico na sociedade atual.

O estudo faz uma contribuição original sobre a percepção dos adolescentes da Geração Z sobre a escola e o processo ensino-aprendizagem. Tal conhecimento poderá subsidiar discussões em diferentes áreas, como a saúde, para propor estratégias de intervenção eficazes e conectadas com a realidade, às necessidade e demandas desse público. Entrementes, estudos com outros desenhos metodológicos podem ampliar o conhecimento apresentado nesse artigo, sobretudo estudos mistos ou com diferentes grupos amostrais. Outros estudos, também, podem aumentar a compreensão da área sobre a temática investigando, por exemplo, variáveis comportamentais relacionadas ao uso das TICs.

\section{REFERÊNCIAS}

1. Silva MAI. Adolescence: resignify it to understand it and act. Rev Enferm UFPE on line [Internet]. 2012 [acesso em: 31 dez. 2017];6(3). Disponível em: https://periodicos.ufpe.br/revistas/revistaenfermagem/article/view/7124.

2. Linne J. Dos generaciones de nativos digitales. Intercom Rev Bras Ciências da Comun [Internet]. 2014 [acesso em: 31 dez. 2017];37(2):203-21. Disponível em: http://doi.org/10.1590/1809-584420149.

3. Franco CP. Understanding digital natives' learning experiences. Rev Bras Linguística Apl [Internet]. 2013 [acesso em: 31 dez. 2017];13(2):643-58. Disponível em: http://doi.org/10.1590/S1984-63982013005000001.

4. Oliveira LB, Honório SRFS. Atração e desligamento voluntário de jovens empregados: um estudo de caso no setor jornalístico. Rev Adm [Internet]. 2014 [acesso em: 31 dez. 2017];49(4):714-30. Disponível em:

http://doi.org/10.5700/rausp1179.

5. Bona AS, Basso MVA. Portfólio de Matemática: um instrumento de análise do processo de aprendizagem. Bolema Bol Educ Matemática [Internet]. 2013 [acesso em: 31 dez. 2017];27(46):399-416. Disponível em:

http://doi.org/10.1590/s0103-636X2013000300005. 
6. Comitê Gestor da Internet no Brasil. Análise dos resultados - TIC Educação 2014. Barbosa AF, coordenação. Pesquisa sobre o uso das tecnologias da informação e comunicação nas escolas brasileiras [Internet]. São Paulo: Comitê Gestor da Internet no Brasil; 2015 [acesso em: 31 dez. 2017]. Disponível em:

http://cetic.br/media/docs/publicacoes/2/TIC_Educacao_2014_livro_eletronico.pdf.

7. Henriques BD, Rocha RL, Madeira AMF. Saúde do adolescente: o significado do atendimento para os profissionais da atenção primária do município de Viçosa, MG. Rev Med Minas Gerais [Internet]. 2010 [acesso em: 31 dez. 2017];20(3):300-9. Disponível em: http://www.rmmg.org/artigo/detalhes/357.

8. Oliveira DL. The use of focus groups to investigate sensitive topics: an example taken from research on adolescent girls' perceptions about sexual risks. Cien Saude Colet [Internet]. 2011 [acesso em: 31 dez. 2017];16(7):3093-102. Disponível em: http://doi.org/10.1590/S1413-81232011000800009.

9. Minayo MCS. Ciência, técnica e arte: o desafio da pesquisa social. In: Minayo MCS. Pesquisa Social: teoria, método e criatividade. Petrópolis: Vozes; 2013. p. 9-29.

10. Bardin L. Análise de conteúdo. Lisboa: Edições 70; 2010.

11. Vygotsky LS. Pensamento e palavra. In: Vigotski LS. A construção do Pensamento e da Linguagem. São Paulo: Martins Fontes; 1934. p. 101-30.

12. Miranda L, Morais C, Alves $P$, Dias $P$. Redes Sociais na aprendizagem: motivação e utilização dos estudantes de ensino superior. In: Moreira JA, Barros DM, Monteiro A. Educação a Distância e e-Learning na web social. Santo Tirso (PT): WHITEBOOKS; 2014. p. 73-95.

13. Schaffer MA, Anderson LJW, Rising S. Public Health Interventions for School Nursing Practice. J Sch Nurs [Internet]. 2016 [acesso em: 31 dez. 2017];32(3):195-208. Disponível em: http://doi.org/10.1177/1059840515605361.

14. Feio A, Oliveira CC. Confluências e divergências conceituais em educação em saúde. Saúde e Soc [Internet]. 2015 [acesso em: 31 dez. 2017];24(2):703-15. Disponível em: http://doi.org/10.1590/S0104-12902015000200024.

15. Silva LO, Molina Neto V. Os sentidos da escola e da Educação Física para estudantes e docentes de uma rede publica municipal. Mov [Internet]. 2014 J [acesso em: 31 dez. 2017];20(3):1133-52. Disponível em:

http://seer.ufrgs.br/index.php/Movimento/article/view/40669.

16. Machado LS, Moraes RM, Nunes FLS, Costa RMEM. Serious games baseados em realidade virtual para educação médica. Rev Bras Educ Med [Internet]. 2011 [acesso em: 31 dez. 2017];35(2):254-62. Disponível em: http://doi.org/10.1590/S0100-55022011000200015.

17. Karime A, Hafidh B, Khaldi A, Aljaam JM, El Saddik A. MeMaPads: Enhancing children's well-being through a physically interactive memory and math games. In: 2012 IEEE International Instrumentation and Measurement Technology Conference Proceedings [Internet]. IEEE; 2012 [acesso em: 31 dez. 2017]. p. 2563-6. Disponível em: http://doi.org/10.1109/I2MTC.2012.6229520.

18. Dias JD, Mekaro MS, Cheng Lu JK, Otsuka JL, Fonseca LMM, Zem-Mascarenhas SH. Serious game development as a strategy for health promotion and tackling childhood obesity. Rev Lat Am Enfermagem [Internet]. 2016 [acesso em: 31 dez. 2017];24:e2759. Disponível em: http://doi.org/10.1590/1518-8345.1015.2759.

19. Mano SMF, Gouveia FC, Schall VT. "Amor e sexo: mitos, verdades e fantasias": jovens avaliam potencial de material multimídia educativo em saúde. Ciência Educ [Internet]. 2009 [acesso em: 31 dez. 2017];15(3):647-58. Disponível em: http://doi.org/10.1590/S1516-73132009000300012.

20. Fonseca LMM, Leite AM, Mello DF, Silva MAI, Lima RAG, Scochi CGS. Tecnologia educacional em saúde: contribuições para a enfermagem pediátrica e neonatal. Esc Anna Nery [Internet]. 2011 [acesso em: 31 dez. 2017];15(1):190-6. Disponível em: http://doi.org/10.1590/S1414-81452011000100027.

21. Leão G, Dayrell JT, Reis JB. Jovens olhares sobre a escola do ensino médio. Cad CEDES [Internet]. 2011 [acesso em: 31 dez. 2017];31(84):253-73. Disponível em: http://doi.org/10.1590/S0101-32622011000200006.

22. Zayapragassarazan Z, Kumar S. Active Learning Methods. NTTC bulletin [Internet]. 2012 [acesso em: 31 dez. 2017];19(1):3-5. Disponível em:

http://www.jipmer.edu.in/sites/default/files/2581_2012_NTTC_Bulletin_2012_Mar.pdf. 